\section{RADIOLOGICAL ChaNGeS IN THE SKULL IN DYSTROPHIA MYOTONICA}

\author{
BY
}

\section{J. E. CAUGHEY, M.D., F.R.C.P., F.R.A.C.P. Physician to the Auckland Hospital, N.Z.}

In a previous endocrine study of dystrophia myotonica Caughey and Brown (1951) made reference to certain radiological abnormalities of the skull in dystrophia myotonica, and suggested that these changes should be regarded as variable features of the disorder. Since that time I have had the opportunity of studying further cases which have presented with similar radiological findings. No mention of these findings has been discovered in the standard textbooks, and this additional account is recorded in the hope that it may stimulate interest and establish the clinical significance of these changes by radiological study of many more cases than one observer can hope to collect.

\section{Historical}

Myotonia was first described by Leyden in 1874 . In 1876 Thomsen, who himself suffered from myotonia, recorded his own symptoms and signs. The combination of myotonia and muscle atrophy was described by Dana in 1888, but it is Déleage (1890) who is usually credited with the first account of dystrophia myotonica. In 1909 Steinert wrote a full description of the disease, and first described changes in the mental state and some of the associated dystrophic features such as premature frontal baldness and gonadal atrophy. At the time, these latter findings were regarded as being merely coincidental. In 1911 Greenfield recorded the constant association of cataract in the disorder, and thereafter the other dystrophic manifestations of the disorder came to be recognized as an essential part of the clinical picture in the fully developed disorder of the "dystrophic" generation.

Few authors have made reference to radiological changes in the skull in these patients. Scharnke and Full (1920) described a large frontal sinus in the presence of a normal pituitary fossa. Rouquès (1931) reported the radiological findings of the skull in four patients. The calvarium was distinctly thickened in three and less so in the fourth. Large frontal sinuses occurred in two, in two the pituitary fossa was small, and in two it was bridged over by an area of calcification. Fagin (1946) reported the occurrence of hyperostosis frontalis in two patients.

\section{Clinical Reports}

This study is based on 13 patients with dystrophia myotonica-all members of the so-called "dystrophic generation" and all presenting myotonia, characteristic muscle-wasting, and various dystrophic lesions such as cataract, gonadal atrophy, and frontal baldness. It is considered that in none of these cases can there be any reasonable doubt about the diagnosis. Most of them have been reported in detail elsewhere, and are here recorded in brief but with full radiological reports.

Case 1.-A farmer aged 45, single, developed weakness and wasting of the arms and legs and myotonia at the age of 27. The weakness progressed until he became almost bedridden. Soon after the onset of the disease he developed bilateral cataract, premature frontal baldness, and gonadal atrophy. Post-mortem findings confirmed the diagnosis of dystrophia myotonica, with the disorder fully developed. Radiological findings:-Skull (Fig. 1): the vault shape was normal; the calvarium was thickened; hyperostosis interna frontalis et parietalis was present; the sinuses were within normal limits; the mandible was normal; the pituitary fossa was small, with a pneumatized dorsum sella; the pineal body was calcified.

Case 2.-A single panel-beater aged 26 presented with auricular flutter in 1945 . Myotonia had been noted two years prior to this. He had the fully developed disease, with myotonia, wasting of the face, arms, legs, and sternomastoid muscles. There was no gonadal atrophy and no cataract. Radiological findings:-Skull: the vault shape was normal and the calvarium thickened, especially in the posterior parietal region; there was a hyperostosis interna frontalis; the frontal sinuses were deep; the sphenoidal sinus was large and the pituitary fossa very small.

Case 3.-A married woman aged 33 developed myotonia at 21 . Wasting and weakness of legs, arms, face, and neck

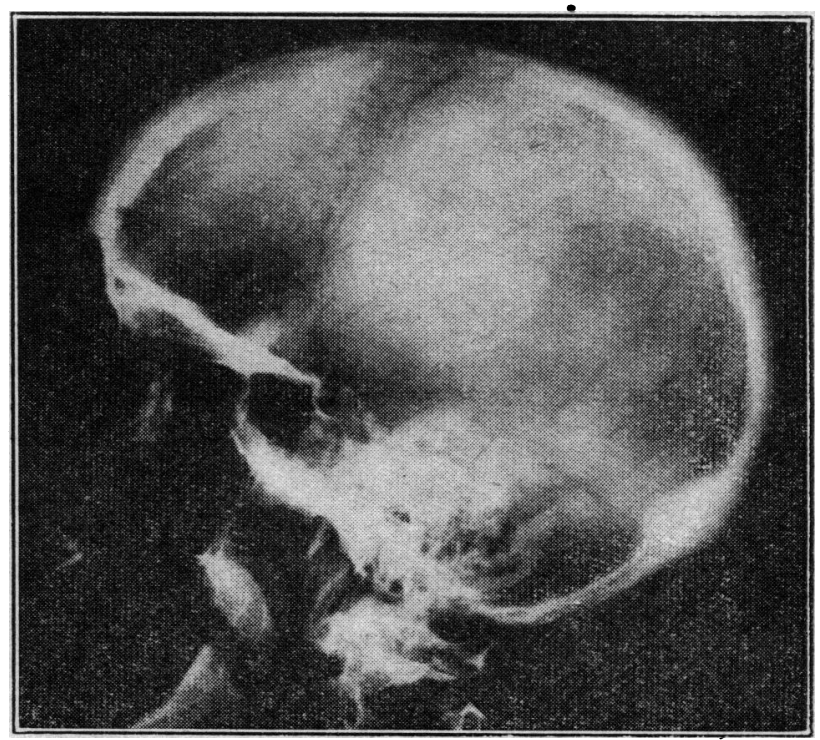

Fig. 1.-Case 1. Calvarium thickened; hyperostosis tiumians; pituitary fossa small.

muscles were apparent at 28 , and bilateral cataract developed at 30. Radiological findings:-Skull: the vault shape was normal and the calvarium thickened throughout, with moderate hyperostosis interna frontalis et parietalis; the sphenoidal sinus was large and other sinuses were within normal limits; there was pneumatization of the dorsum sella ; the pituitary fossa was small, and the pineal body was calcified.

Case 4.-A male factory-hand aged 27 had for two years noted myotonia, weakness of the neck muscles, wasting of the forearms and legs, and frontal baldness. He presented with myotonia and characteristic muscle-wasting. There were no lenticular opacities, and no gonadal atrophy was noted. Radiological findings:-Skull: the calvarium was thickened and there was hyperostosis interna frontalis; the sinuses were normal in size; the pituitary fossa was small.

Case 5.-A military pensioner aged 32 first noted myotonia while a prisoner of war in Germany in 1942. In 1946 he presented with myotonia, wasting of sterno-mastoids, forearms, and legs. There was cataract and frontal baldness, but gonadal atrophy was not noted. Radiological findings:-Skull: the calvarium was normal; there was a very grossly calcified falx cerebri, which was responsible in part for the appearance of a nebula frontalis ; no definite hyperostosis was present ; the pituitary fossa was normal to small ; all sinuses were large.

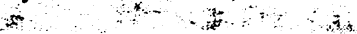

Case 6.-A carpenter aged 41 developed failure of potentia at 34. Myotonia was noticed four years later, and wasting 
of face, neck, forearms, and legs became apparent. He presented a characteristic picture, with myotonia, musclewasting, and gonadal atrophy. Radiological findings:Skull: there was no thickening of the calvarium; the frontal and sphenoidal sinuses were extensive and deep; the pituitary fossa was small; the dorsum sella was completely pneumatized; the jaw was prognathous.

Case 7.-A housewife aged 51 had noticed weakness of her neck muscles since she was 30 . The sterno-mastoid muscles had wasted, there was progressive wasting and weakness of her forearms and legs, and she had bilateral cataract. Mechanical myotonia was present. The anklejerks were absent. Radiological findings:-Skull: ther? was thickening of the whole calvarium with loss of differentiation of the cortex and the diploe and extensive hyperostosis interna frontalis. The sinuses were normal and the pituitary fossa was very small, with calcification near the floor. There was no pneumatization of the dorsum. sella.

Case 8.-A labourer aged 28 , who had been backward at school, at 17 noticed difficulty in relaxing his grasp, and his arms and legs became progressively weaker,and wasted. Visual deterioration had been apparent for five years. He presented with myotonia, muscle-wasting, bilateral lenticular opacities, and frontal baldness. The gonads were not obviously atrophic. Radiological findings:-Skull: the vault was normal in size and the calvarium was thickened; there was extensive hyperostosis interna frontalis et parietalis; the vertical component of the frontal sinus was normal, but the horizontal component extended almost to the anterior clinoids; the pituitary fossa was very small, and the dorsum sella was thick and partially pneumatized.

Case 9.-A grocer aged 33, who was backward at school, first noticed myotonia at 13 years. Wasting of face, arms, and legs developed two years later. He presented with marked myotonia, wasting of sterno-mastoid muscles, and face, forearms, and legs. There was marked gonadal atrophy, but there were no cataracts. Radiological findings:-Skull (Fig. 2): the vault was small, globoid, and microcephalic; the calvarium was thickened but of normal density; the sinuses were extensive and deep, especially the sphenoids, which extended into the posterior clinoid processes; the pituitary fossa was very small and the jaw markedly prognathous.

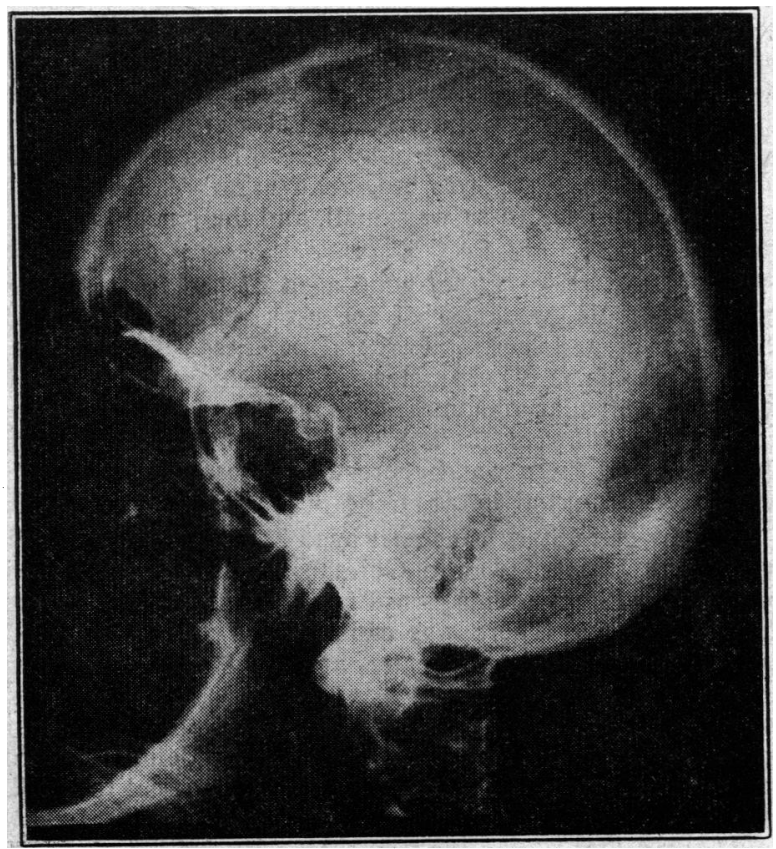

Fio: 2-Case 9. Calvarium thickened; pituitary fossa very small; jaw prognathous; sinuses extensive.
Case 10--A spinster aged 45 had been admitted to a mental hosital nine years previously. Six years later she developed myotonia, and in 1950 presented with bilateral cataract, myotonia, and wasting of the face, sterno-mastoid muscles, forearms, and legs. Radiological findings :-Skull: there was marked hyperostosis interna frontalis; the floor of the anterior fossa was more vertical than usual and the pituitary fossa was small; the frontal sinus showed a large horizontal component and a very large vertical component ; the sphenoidal sinus was large and the antra were normal; the jaw was prognathous.

Case 11.-A housewife aged 47 developed bilateral cataract nine years previously. When examined she presented myotonia of grasp and some weakness of the sterno-mastoid muscles. Radiological findings:-Skull: the calvarium was thickened; there was hyperostosis interna frontalis; the pituitary fossa was small and the sinuses were all normal.

Case 12.-A farmer aged 42 first noticed myotonia in 1941 , and weakness and wasting of his arms and legs developed a year later. He presented with myotonia and wasting of the sterno-mastoid muscles, forearms, and legs. There was bilateral cataract, with frontal baldness, gonadal atrophy, and areflexia. Radiological findings:-Skull: the calvarium was normal; there was no hyperostosis; the pituitary fossa was small ; the frontal sinuses were extensive and the sphenoidal sinus was large.

Case 13.-A spinster aged 42 had for 15 years noticed an inability to relax her grasp. For 15 months her legs had been weak and wasting had developed. On examination there was wasting of the face, forearms, and legs, and the sterno-mastoid muscles had wasted completely. There was myotonia of grasp. Radiological findings:-Skull: there was marked thickening of the calvarium, the average thickening being approximately $1.5 \mathrm{~cm}$. This thickness was evenly distributed and involved all the bones of the vault. There was also evidence of some hyperostosis interna frontalis. The pituitary fossa was also abnormally small. Both anterior and posterior clinoid processes and the dorsum sella were well developed.

\section{Discussion}

These 13 patients all suffered from dystrophia myotonica and all were members of the so-called "dystrophic generation." It is realized that in assessing the size of the pituitary fossa and the size of the sinuses in the standard views the radiologist bases his opinion largely on subjective impression, as strictly accurate measurement is not always possible.

In the above reports the size of the pituitary fossa is classified as normal, small, or very small-" small" indicating a sagittal diameter below $9 \mathrm{~mm}$. and/or a vertical diameter below $6 \mathrm{~mm}$.; "very small" indicating measurements below $6 \mathrm{~mm}$. and/or $4 \mathrm{~mm}$. respectively for the same diameters. With two exceptions the magnification distortion was known to be the same in all cases.

The pituitary fossa was small in seven cases, normal to small in one, and very small in five. Thickening of the calvarium occurred in nine cases. The next most constant finding was the presence of hyperostosis interna frontalis et parietalis, which was noted in nine and was pronounced in three of these. It is notable that five of these cases were males aged from 26 to 45 years. Enlargement of the sinuses was noted in eight, and in two the mandible was elongated.

In view of these findings it seems evident that these radiological abnormalities of the skull must come to be accepted as one of the variable dystrophic features of dystrophia myotonica. 


\section{Summary}

Thirteen cases of dystrophia myotonica are reported in brief. All presented some radiological abnormalities of the skull. The most constant changes were a small to very small pituitary fossa, thickening of the calvarium, and hyperostosis interna. There was enlargement of the sinuses in some and in two the mandible was elongated. We believe the high incidence of these changes cannot be coincidental, and it is held they should now come to be accepted as some of the variable features of dystrophia myotonica.

It is a pleasure to thank various physicians who have given me access to their cases, and Dr. Alexander and Dr. Rolleston for reviewing the radiological reports.

\section{REFERENCES}

Caughey, J. E.. and Brown (1951). Quart. J. Med. In press. Dana, C. L. (1888). Med. Rec., 33, 433

Déléage, F. (1890). Etude clinique sur la maladie de Thomsen Thèse de Paris, Lejay édit., Paris.

Fagin, I. D. (1946). J. Mich. med. Soc., 45, 500.

Greenfield, J. G. (1911). Rev. Neurol. Psych.. 9, 169.

Leyden, E. (1874). Klinik der Rückenmarkskrankheiten.

Rouquès, Lucien (1931). La Myotonie atrophique, p. 39. Amédée Legrand, Paris.

Scharnke and Full (1920). Quoted by L. Rouquès, Z. ges. Neurol Psychiat., 61, 146

Steinert, H. (1909) Disch. Z. Nervenheilk., 37, 38.

Thomsen, J., Arch. Psychiat., 1876, 6, 706; 1892, 24, 918.

\section{BULLOUS LESIONS IN LEUKAEMIA}

\section{BY}

\section{RONALD SCUTT, M.B., M.R.C.P.Ed. \\ Late Senior Dermatological Registrar, Norfolk and Norwich Hospital}

The skin manifestations of leukaemia are many and varied : Arzt and Fuhs (1929) have mentioned eczematous, erythema-multiforme-like, purpuric, zosteriform, urticarial, bullous, and rupial lesions, in addition to exfoliative erythrodermia and the specific leukaemic deposits occurring in the form of small papules, nodules, or large tumours.

Wiener (1947) states that bullous eruptions may precede generalized exfoliative erythrodermia in lymphatic leukaemia, and that they are often encountered in the early stages of monocytic leukaemia. It would seem that remarkably few cases of leukaemia with bullous lesions have, in fact, been recorded. In an analysis of a series of 445 cases of the reticuloses (including 160 cases of leukaemia) at the Los Angeles County Hospital, Epstein and MacEachern (1937) reported cutaneous involvement in $194(43.5 \%)$. Bullous or vesicular lesions were seen in six cases, of which three were Hodgkin's disease, two myeloid leukaemia, and one lymphosarcoma. No bullous eruption was seen in any cases of lymphatic, monocytic, or acute leukaemia.

Margarot, Rimbaud, and Roche (1935) reported the case of a boy of 12 years, who was first seen with a purulent bullous eruption on the lower limbs, associated with pyrexial attacks. It was only when, five months later, he developed a generalized erythrodermia associated with palpable lymph nodes that a blood count revealed a leucocytosis of 34,000 per c.mm., of which $91 \%$ were primitive cells of the lymphatic series. The diagnosis of acute leukaemia was confirmed by the subsequent course of the disease, with the development of ulcerative stomatitis and a severe bleeding tendency, and death within four months of establishment of the diagnosis.
Remenovsky (1935) described the case of a 51-year-old patient with an acute leukaemia (leucocytes 83,600 per c.mm., $91.7 \%$ immature lymphocytes). After systemic arsenic the blood picture changed dramatically, the total leucocyte count falling to 6,000 per c.mm., $40 \%$ being lymphocytes. At the same time bullous eruptions developed on the wrists and forearms.

It would seem that the few recorded cases of bullous dermatoses have been associated with acute leukaemia. The following case of chronic lymphatic leukaemia is therefore of particular interest because of several unusual features : the manner of presentation as a bullous eruption on the palms and soles; the remarkable bluish infiltrated erythematous eruption on the face ; and the presence of four other skin manifestationsnamely, purpura, erythema-multiforme-like lesions, cellulitis, and the specific papular infiltrate.

\section{Case Report}

The patient, a married woman aged 65 , first reported to the skin clinic at the Norfolk and Norwich Hospital on July 26, 1950. She gave a history of a bullous eruption which started one month previously on the right sole, later involving the left sole and the left palm. She had had a sore throat at the onset. There was no relevant previous history.

On examination bullae up to $1 \mathrm{~cm}$. or more in diameter were scattered over the soles of both feet. The dorsa of the feet and webs of the toes were quite normal. There were a few confluent bullae on the left thenar eminence. All lesions contained clear fluid at this stage. General examination revealed no abnormalities. Scrapings taken from the feet showed no evidence of fungus infection.

In the absence of a history of possible contact irritants, it was thought that the eruption was in the nature of a bullous pompholyx, and treatment was given in the form of baths of potassium permanganate, and phenobarbitone, $\frac{1}{2} \mathrm{gr}$. (32 $\mathrm{mg}$.) thrice daily. The local treatment was changed after a week to Castellani's paint, and later to $0.5 \%$ gentian violet. No progress was made, and after a month both palms were severely involved.

In view of the discomfort and the lack of response to treatment, the patient was admitted on October 4. By this time bullae had begun to appear on the dorsa of both feet, and some haemorrhagic elements were present (Figs. 1 and 2). Glands were palpable in both axillae and groins, but the spleen was not felt.

A blood examination on October 11 showed a total leucocyte count of 79,800 per c.mm., of which $91 \%$ were lymphocytes. On November 3 her leucocytes had gone up to 123,200 per c.mm., of which $90 \%$ were lymphocytes, $4 \%$ monocytes, and $6 \%$ polymorphs. (Her haemoglobin at this stage was $98 \%$.) No primitive cells were seen. Large numbers of smear cells were present in stained films. The platelets. were not accurately estimated at the time, but the impression was that they were reduced. A sternal marrow examination on November 15 confirmed the picture of chronic lymphatic leukaemia.

A course of superficial $x$ rays (to a total of $450 \mathrm{r}$ ) produced a dramatic effect on the bullae. After four weeks the hands were completely normal again and there were only a few small lesions on the dorsa of the feet.

During the period in hospital she developed cellulitis of the legs; this responded rapidly to penicillin.

One week before discharge on November 24 a feu scattered pinhead-sized erythematous papules had developed on the anterior surfaces of the knees and thighs. When she was seen in the out-patient department on December 7 the hands were still normal but new purulent bullae had appeared on the soles. Both feet showed a diffuse erythema 